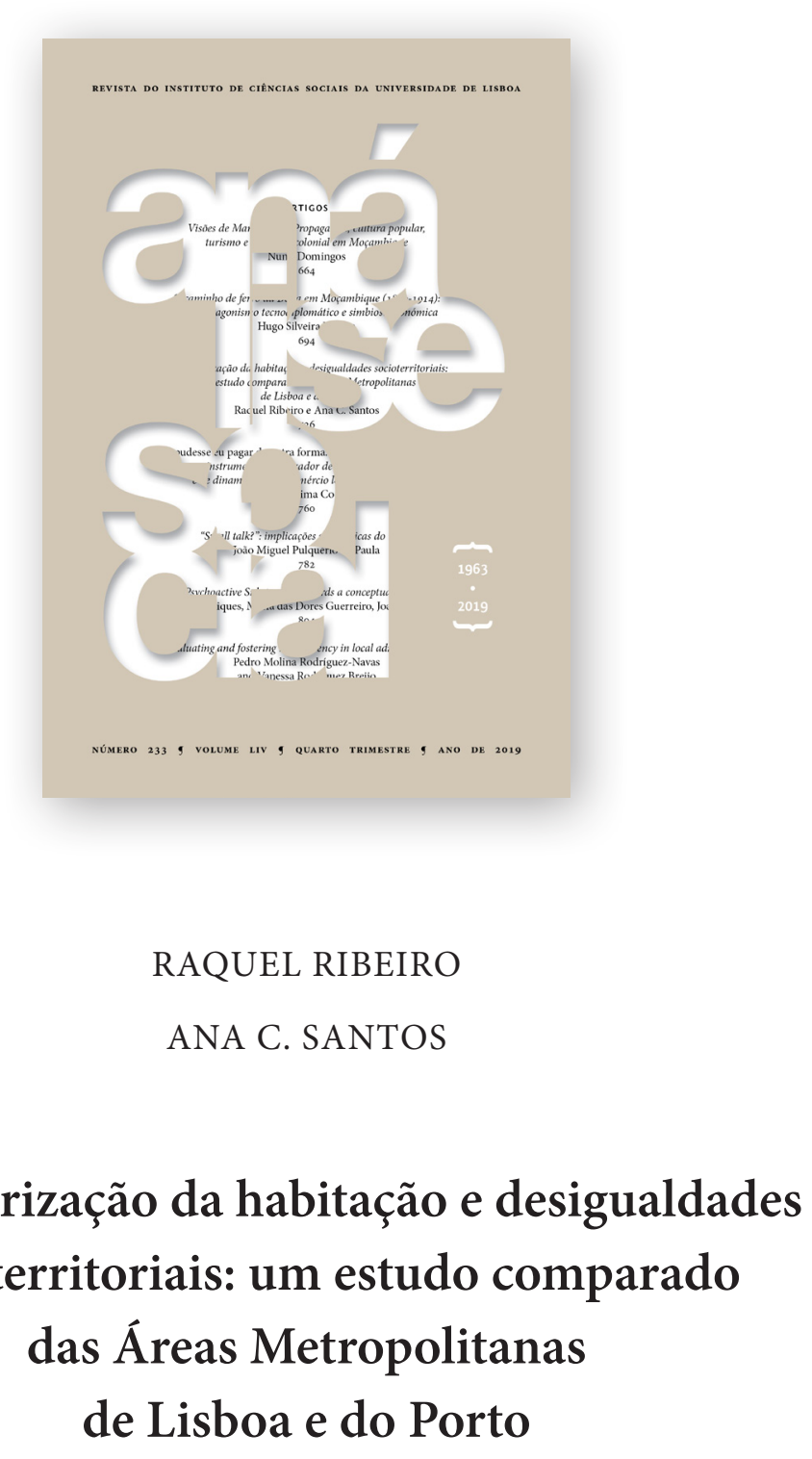

\title{
Financeirização da habitação e desigualdades socioterritoriais: um estudo comparado das Áreas Metropolitanas de Lisboa e do Porto
}

\author{
Análise Social, LIV (4. $\left.{ }^{\circ}\right), 2019$ (n. $\left.{ }^{\circ} 233\right)$, pp. 726-758 \\ https://doi.org/10.31447/ASOo032573.2019233.03 \\ ISSN ONLINE 2182-2999
}


Análise Social, 233, LIV $\left(4 \cdot^{\circ}\right)$, 2019, 726-758

Financeirização da habitação e desigualdades socioterritoriais: um estudo comparado das Áreas Metropolitanas de Lisboa e do Porto. O crédito hipotecário marca a provisão da habitação em Portugal a partir do início da década de 1990, constituindo um importante mecanismo de reprodução de desigualdades sociais e territoriais. Com base nos dados dos Censos de 2011, este artigo analisa a relação entre formas de provisão da habitação e heterogeneidade socioterritorial nas Áreas Metropolitanas de Lisboa (AML) e do Porto (AMP). Conclui que a financeirização da habitação é um fenómeno mais significativo na AML, tendo-se verificado nesta área metropolitana uma relação mais intensa entre finança e habitação, associando nova construção e dispersão populacional a crédito hipotecário.

PALAVRAS-CHAVE: financeirização; habitação; desigualdades socioterritoriais; Áreas Metropolitanas de Lisboa e do Porto.

Financialized Housing and Socioterritorial Inequalities: A Comparative Study of Lisbon and Porto Metropolitan Areas. Mortgage credit marks housing provision in Portugal since the beginning of the 1990 s, becoming an important mechanism of reproduction of social and territorial inequalities. Based on data from the Census of 2011, this article analyzes the relationship between forms of housing provision and socioterritorial heterogeneity in the Metropolitan Areas of Lisbon and Porto. The article concludes that financialization of housing is mostly a phenomenon of the Metropolitan Area of Lisbon, where a closer relationship was found between finance and housing, associating new construction and population dispersion with mortgage credit.

KEYWORDS: financialization; housing; socioterritorial inequalities; Lisbon and Porto Metropolitan Areas.

https://doi.org/10.31447/Asooo32573.2019233.03 


\section{Financeirização da habitação e desigualdades socioterritoriais: um estudo comparado das Áreas Metropolitanas de Lisboa e do Porto ${ }^{1}$}

\section{INTRODUÇÃO}

O crescimento do crédito à habitação constitui um dos desenvolvimentos mais marcantes do capitalismo contemporâneo, em particular no âmbito daquilo que a literatura crítica designa por "financeirização" e que se refere aos processos que conduziram ao crescente peso económico e à influência política do setor financeiro e dos seus agentes nas economias, empresas, nos Estados e famílias (Epstein, 2005; Aalbers, 2016). No último quartel do século $\mathrm{xx}, \mathrm{o}$ crédito à habitação passou de um para dois terços do crédito total concedido pela banca, substituindo a sua tradicional vocação de financiamento às empresas (Jordá, Schularick e Taylor, 2015). Esta evolução do mercado hipotecário é reveladora do papel da habitação nas economias capitalistas mais desenvolvidas ao contribuir como nenhum outro setor para a expansão da finança. Talvez mais significativo ainda seja o papel que a habitação assume na transmissão dos impactos socioeconómicos e territoriais da financeirização, seja através da interação com atividades económicas conexas (por exemplo a construção, o imobiliário, o turismo) em detrimento de outras

1 Este trabalho é financiado pelo FEDER - Fundo Europeu de Desenvolvimento Regional através do COMPETE 2020 - Programa Operacional Competitividade e Internacionalização (POCI) e por fundos nacionais através da FCT - Fundação para a Ciência e Tecnologia, no âmbito do projeto FINHABIT, ref. ${ }^{a}$ PTDC/ATP-GEO/2362/2014 - POCI-01-0145-FEDER - 016869 . 
com maior potencial socioeconómico, seja através da provisão deste bem tão essencial às famílias. ${ }^{2}$

Vários autores já notaram que a financeirização da habitação, isto é, o crescente peso da finança e dos seus agentes na provisão deste bem, está intrinsecamente relacionada com a sua mercadorização, ou seja, com a sua transformação em produto concebido para transação no mercado, tendo como principal propósito a realização do seu valor de troca e não o seu valor de uso ou a satisfação das necessidades habitacionais (cf. por exemplo Aalbers, 2016). A financeirização da habitação associa-se também, e cada vez mais, à metamorfose da habitação em ativo financeiro, isto é, em investimento baseado na expectativa de valorização rápida do seu valor de troca (entre outros, Fernandez, Hofman e Aalbers, 2016). Num estudo recente sobre as economias capitalistas mais avançadas, incluindo Portugal, Jordá et al. (2017) mostram que, de facto, a habitação se tornou o melhor investimento do ponto de vista das taxas de rendibilidade oferecidas e da estabilidade destas, apesar da implosão de algumas bolhas imobiliárias. ${ }^{3}$

Estas tendências sistémicas também se verificaram em Portugal. O crédito concedido pela banca ao setor privado, incluindo famílias e empresas, cresceu consideravelmente desde o último quartel do século passado, multiplicando o seu valor 63 vezes entre 1980 e 2010 , ano em que atingiu o montante mais elevado, equivalente a 260000 milhões de euros. Este crescimento deveu-se, em grande medida, à evolução dos empréstimos concedidos às famílias, que no mesmo período passaram de $12.4 \%$ a $54.4 \%$ do total do crédito concedido pela banca, constituindo $60.7 \%$ deste crédito em janeiro de $2018 .{ }^{4}$ Esta evolução

2 A evolução recente do crédito à habitação deve-se a um conjunto de transformações regulatórias dos mercados financeiros, em geral, e da banca, em particular, permitindo o surgimento de novos produtos financeiros, como os títulos de crédito hipotecário, que aumentaram a liquidez da banca para a concessão de novo crédito, assim estimulando a criação de novos títulos, que por sua vez alimentam a concessão de novo crédito (Crotty, 2009). Embora estas transformações sejam também elas constitutivas e caracterizadoras do processo de financeirização da habitação, o seu resultado foi o aumento extraordinário do crédito à habitação. Assim, ao longo deste artigo tomar-se-á o crédito à habitação como um indicador da financeirização da habitação. Para uma abordagem mais abrangente consulte-se Santos, Teles e Serra (2014); Rodrigues, Santos e Teles (2016a); Santos (2019).

3 Em termos médios, para o conjunto dos 16 países do estudo, a taxa de rendibilidade da habitação é de $8.0 \%$, enquanto a taxa de rendibilidade do segundo ativo mais rentável, as ações, é de $6.7 \%$, equivalendo a taxa de rendibilidade das Obrigações do Tesouro a 2.5\%. Estes valores são, respetivamente, $8.5 \%, 7.1 \%$ e $2.8 \%$ para Portugal.

4 Cálculos próprios a partir dos dados disponíveis em https://www.bportugal.pt/estatisticas web/(S(prszohv5zsqsjbqltupkm2rb))/FiltroSeries.aspx?IDs=122153:826445, consultado a 10-04-2018. 
reflete o comportamento dos empréstimos à habitação, que não só constituem a maior parte dos empréstimos a particulares, como viram o seu peso aumentar no período de 1980 a 2010 , passando de $67.4 \%$ para $80.1 \%$. Por sua vez, o crédito concedido às empresas foi crescentemente dedicado aos setores da construção e das atividades imobiliárias, tendo o seu valor agregado passado de $9.9 \%$ para $35.6 \%$ do total do crédito concedido às sociedades não financeiras no mesmo período. ${ }^{5}$

Apesar de já ser possível identificar nos finais do século XIX e inícios do século $\mathrm{xx}$ impactos diferenciados na provisão de habitação decorrentes do recurso ao crédito bancário, é a partir dos finais do século xx que esse impacto se torna significativo. ${ }^{6}$ A provisão da habitação no país passou a estar mais dependente do crédito para aquisição de alojamentos novos e até mesmo de uma segunda residência. Entre 1995 e 2012, o peso dos empréstimos à habitação no rendimento disponível das famílias quadruplicou, aumentando de $23 \%$ para 91\% (ECRI, 2016). Entre 1991 e 2011, o número de alojamentos familiares de residência habitual cresceu $31 \%$ e o dos alojamentos de residência secundária ou uso sazonal $300 \%$, enquanto o número de alojamentos vagos que não se destinam nem à venda nem ao arrendamento registou um crescimento de $51 \% .^{7}$ No mesmo período, o número de alojamentos ocupados pelos proprietários aumentou $48 \%$, passando o regime de propriedade privada a representar, em 2011, cerca de $73 \%$ do total dos alojamentos, quando este valor era

5 O crédito concedido ao setor da construção passou de $6.5 \%$ para $24.8 \%$ entre 1980 e 2005 , ano em que atingiu o peso relativo mais elevado. O crédito concedido ao setor da atividade imobiliária passou de $3.3 \%$ para $14.3 \%$ entre 1980 e 2010 , ano em que atingiu o peso relativo mais elevado. O crédito concedido ao setor do turismo (isto é, alojamento, restauração e similares) começou a crescer apenas a partir da segunda metade da década de 1990, atingindo o valor de $2.1 \%$ em 2000; desde então tem crescido gradualmente, sendo que em janeiro de 2018 representava $6.3 \%$ do crédito bancário. Cálculos próprios a partir dos dados disponíveis em https:// www.bportugal.pt/estatisticasweb/(S(prszohv5zsqsjbqltupkm2rb))/FiltroSeries.aspx?IDs=12 2153:826445, consultado a 10-04-2018.

6 Com efeito, reportando-se às estratégias de habitação entre 1880 e 1940, Teixeira (1992) sublinha o papel do recurso ao crédito no tipo e qualidade da habitação construída e na forma de ocupação do solo urbano, mais viável economicamente em Lisboa, onde os salários eram mais elevados, por comparação ao Porto. Focando-se na segunda metade do século xx, Castela (2019) refere o papel do Fundo do Fomento da Habitação, criado em 1969 com o propósito de estimular a iniciativa privada e a indústria de construção, favorecendo sobretudo os grupos sociais mais privilegiados.

7 O crescimento e a relevância dos alojamentos de residência secundária ou uso sazonal estão bem patentes na sua evolução em termos absolutos, passando de 377608 , em 1991, para 1133300 alojamentos em 2011, constituindo assim cerca de $20 \%$ do total dos alojamentos familiares (5859540) neste ano. 
$65 \%$ em $1991 .^{8}$ Esta evolução foi mais intensa nas cidades de maior dimensão, nomeadamente nos municípios pertencentes às Áreas Metropolitanas de Lisboa e Porto, acompanhando o crescimento urbano das principais metrópoles do país neste período (Ribeiro e Santos, 2017). ${ }^{9}$

As referidas transformações na provisão da habitação em Portugal são, em parte, o resultado de políticas públicas, incluindo desenvolvimentos relevantes no setor financeiro no quadro do processo de integração europeia, que permitiram o crescimento rápido do crédito hipotecário (Rodrigues, Santos e Teles, 2016a e 2016b), e das políticas de habitação que há muito vêm promovendo um modelo privado de provisão assente no crédito hipotecário (Serra, 2002; Guerra, 2011; Santos, Teles e Serra, 2014). A composição da despesa pública neste domínio é muito reveladora desta opção política. Entre 1987 e 2011, o montante total de bonificações a empréstimos à habitação e de incentivos fiscais para a aquisição de casa própria constituiu cerca de $73 \%$ da despesa pública em habitação, contrastando com os $2 \%$ destinados à promoção direta (IHRU, 2015).

Contudo, o acesso ao mercado hipotecário não foi homogéneo, do ponto de vista social ou territorial, concentrando-se nos grupos socioeconómicos mais privilegiados e nos territórios com maior densidade populacional. Segundo dados do INE e do Banco de Portugal, em 2013, 58\% das famílias de rendimento mais elevado tinham uma hipoteca sobre a sua residência principal, ao passo que no caso das famílias de rendimento mais baixo este valor situava-se apenas nos $11 \%$; a média para o conjunto das famílias equivalia a $33 \%$ (Costa, 2016, p. 30). ${ }^{10}$ Num estudo exploratório, Ribeiro e Santos (2018) voltaram a verificar este padrão socioeconómico nas três escalas geográficas consideradas: regiões do continente, Áreas Metropolitanas de Lisboa e Porto e localidades de diferentes dimensões populacionais. Esta composição socioeconómica do mercado hipotecário é muito reveladora da capacidade de expansão da finança

8 Cf. https://www.ine.pt/xportal/xmain?xpid=INE\&xpgid=ine_indicadores\&indOcorrCod $=0006332 \&$ contexto $=$ bd\&selTab $=$ tab2, consultado a 10-04-2018.

9 Entre 1981 e 2011 a proporção de alojamentos com encargos de compra no total de alojamentos de residência habitual aumentou em todos os municípios das duas áreas metropolitanas. Se em Lisboa e no Porto o aumento foi, em média, de cerca de 18 pontos percentuais, este aumento foi superior a 30 pontos percentuais nos municípios suburbanos de Alcochete, Mafra, Moita, Montijo, Palmela, e Sesimbra na AmL e Gondomar, Maia, Valongo, Vila Nova de Gaia, e Vila do Conde na Amp (Ribeiro e Santos, 2017).

10 Ao contrário do que aconteceu, por exemplo, com a expansão do mercado de crédito subprime nos EUA, em Portugal esta expansão não se dirigiu às classes subalternas, com um elevado risco de incumprimento, mas sim às famílias com rendimentos mais elevados e, consequentemente, com melhores garantias de solvência, o que permitiu conter o impacto da crise financeira mundial sobre as famílias quando o desemprego disparou. 
e de homogeneização de espaços tão distintos, reproduzindo e ampliando desigualdades sociais. No entanto, também foram observadas algumas diferenças territoriais, registando-se um maior envolvimento das famílias com a finança nas áreas de maior densidade populacional e na principal área metropolitana do país, a Área Metropolitana de Lisboa. Estes resultados sugerem um efeito de urbanidade na relação entre as famílias e a finança, que se manifesta não só numa maior subscrição de produtos e serviços financeiros, mas também no acesso que se generaliza aos diferentes estratos socioeconómicos. Porém, os impactos socioterritoriais destas relações não estão ainda suficientemente identificados. O presente artigo tem como objetivo analisar esta questão. Fá-lo em dois momentos, primeiro, identifica processos de organização socioterritorial do crédito à habitação nas duas maiores áreas metropolitanas do país, segundo, avalia criticamente os impactos diferenciados da habitação financeirizada nas Áreas Metropolitanas de Lisboa (AML) e Porto (AMP).

$\mathrm{O}$ artigo começa por discutir o papel da habitação na produção de desigualdades socioterritoriais e o papel da financeirização na intensificação destas mesmas desigualdades. De seguida, recorrendo a análises multivariadas sobre dados dos Censos de 2011 para as freguesias da AML e AMP, analisa as diferenças encontradas nas duas áreas metropolitanas. Por fim, apresenta as principais conclusões do estudo comparado, concluindo que a financeirização da habitação é um fenómeno mais expressivo e que produz impactos socioeconómicos e territoriais mais diferenciados na AML do que na AMP.

\section{HABITAÇÃO, FINANÇA E DESIGUALDADES SOCIOTERRITORIAIS}

A habitação é um relevante mecanismo de diferenciação e reprodução de desigualdades sociais e territoriais. Se, por um lado, a condição das várias classes sociais determina onde e como vive cada uma, por outro lado, a diferenciação socioespacial que a habitação dita tem impactos não negligenciáveis no próprio território, podendo reproduzir e criar novas desigualdades.

Há muito que esta relação entre habitação e desigualdades socioterritoriais vem sendo tratada na literatura, principalmente nas áreas da geografia e sociologia urbana, e com especial incidência em contextos de forte crescimento populacional com acentuada diferenciação social. Lefebvre (1968), Castells (1973) e Harvey (1973) ofereceram os contributos seminais do que é hoje uma vasta agenda de investigação. O papel da habitação na (re)produção de desigualdades socioeconómicas e espaciais está também bem documentado no caso português, incluindo as duas principais áreas metropolitanas, Lisboa e Porto (cf. nomeadamente Barata-Salgueiro, 1992 e 2001; Guerra, 1997 e 2011; Ferrão, 2002 e 2003; Malheiros e Vala, 2004), e continua a ser um objeto 
de pesquisa de grande interesse entre cientistas sociais (entre outros, Nunes, Mota e Campos, 2012; Carmo, Cachado e Ferreira, 2015; Seixas et al., 2015; Alves, 2016; Santos, 2016; Lestegás, Lois-Gonzáles e Seixas, 2018).

Barata-Salgueiro (1992, pp. 352-353) associa a segregação das áreas residenciais ao "processo de mutação da cidade tradicional em metrópole, que acompanha o desenvolvimento e penetração do modo de produção capitalista". Segundo a autora, o modo de produção capitalista impõe uma organização do espaço que assenta "numa segregação espacial de raiz económica das diversas atividades urbanas que, no caso da habitação, é também social, porquanto os vários estratos sociais se encontram separados em termos de residência". Tal se deve à transformação da habitação em mercadoria, isto é, um bem que é produzido para ser transacionado no mercado, e à segmentação do mercado de habitação em função do seu preço, que geralmente varia inversamente à distância relativamente ao centro, mas não só. Tal significa que apenas os mais ricos conseguem aceder às localizações mais centrais e que proporcionam maior qualidade de vida, localizações essas que geralmente detêm também mais prestígio e por essa razão constituem as opções locativas dos grupos de maiores rendimentos.

No seu estudo sobre Lisboa, e baseando-se nos Censos de 1991, Barata-Salgueiro (2001) dá conta da expansão, essencialmente não planeada, desta área metropolitana, destacando o papel do investimento público em transportes, que permitiu a aproximação das duas margens, estendendo assim o território da área metropolitana. Este investimento em acessibilidades facilitou a maior dispersão do povoamento, fomentando a construção de residências (primárias e secundárias), bem como uma maior diversidade da ocupação do território metropolitano, com uma distribuição funcional bem delimitada do ponto de vista de comércio, serviços, indústria e habitação. O forte crescimento demográfico resultante das migrações, internas e externas, e a ausência de uma política de promoção direta da habitação, por sua vez, reforçaram a segregação espacial por via de uma intensificação da homogeneidade social e do edificado. Mas a AML tem sofrido também processos de diversificação, sobretudo em áreas que passaram por fases de modernização mais recente, e que estão a constituir-se de forma fragmentada e polarizada. Isto significa que "[s]obre o substrato herdado da cidade industrial a cidade pós-industrial constrói-se como uma cidade fragmentada onde se identificam enclaves diferenciados e áreas mistas". Exemplos destes fenómenos são os processos de nobilitação que "através da renovação ou modernização pontual, traz grupos de maior poder económico para o seio de bairros populares", a persistência de alojamentos degradados lado a lado com imóveis de luxo, "devido à inércia associada às diferenças de ritmo da transformação urbana que opera em 
pequenas extensões sem cuidar das suas margens", e novas orientações na habitação social "que visam a procura de soluções mais integradas e menos segregadas" (Barata-Salgueiro, 2001, p. 185).

Com base nos Censos de 2011, Santos $(2014,2016)$ confirma a persistência de heterogeneidade social e espacial na AML, onde se sobrepõem diferenças territoriais e sociais, e mostra como as dinâmicas de diferenciação socioterritorial se associam a formas diferenciadas de vivência e uso do espaço. Por exemplo os centros urbanos, em especial o município de Lisboa, são os espaços que oferecem os melhores recursos territoriais às populações que neles habitam, incluindo sistemas de transportes públicos, oportunidades de trabalho, serviços e equipamento. Pelo contrário, os territórios suburbanos massificados nos concelhos limítrofes de Lisboa enfrentam os maiores desafios, estando a população residente significativamente mais condicionada aos meios de transporte existentes, públicos ou privados, para aceder aos recursos disponíveis nos centros urbanos. Não obstante, a AML não deixa de ser também um território heterogéneo e fragmentado "onde, por oposição ao domínio de grupos socialmente homogéneos, que ocupam manchas contíguas bem identificáveis de nível macro, se observam combinações mais complexas com vizinhanças polarizadas ou enclaves de escala micro" (Santos, 2014, p. 14).

Centrando-se também na $\mathrm{AML}$, e recorrendo às categorias socioespaciais de Santos (2014, 2016), Carmo, Cachado e Ferreira (2015) identificam maiores vulnerabilidades habitacionais e socioeconómicas nas áreas classificadas como suburbanas massificadas da periferia, onde se verifica uma maior incidência de problemas com a habitação e um maior grau de insatisfação com o local de residência por parte dos inquilinos de alojamentos arrendados. Os autores do estudo concluem que "persiste [...] uma desigualdade no conforto e nas condições físicas dos alojamentos, que variam em função da classe social” (idem, p. 16).

De modo análogo, mas focando-se mais detalhadamente na cidade do Porto, Alves (2016) conclui que a desigualdade socioeconómica reforçou a separação social de classes na geografia urbana, com os grupos profissionais socialmente mais reconhecidos e qualificados a residir na parte ocidental da cidade e os de baixo nível de qualificação significativamente mais concentrados em alojamentos de habitação social localizados na parte oriental.

Por fim, a tipologia do INE (2014) de padrões socioeconómicos, construídos também a partir dos dados dos Censos de 2011 para a AML e AMP, não só revela "um território heterogéneo e fragmentado tendo em conta as características do parque habitacional e da população residente" (p. 13), como permite concluir que o nível de heterogeneidade é mais acentuado na AML do que na AMP, "dada a distribuição territorial e populacional mais equitativa entre 
as várias classes socioeconómicas no território metropolitano de Lisboa" (p. 13).

Estes estudos ilustram a importância da habitação na produção de desigualdades socioeconómicas e territoriais, contudo não abordam diretamente a explosão do crédito à habitação e o seu papel na produção destas desigualdades, que é um dos elementos mais marcantes da provisão da habitação em Portugal nas últimas duas a três décadas, como vimos.

No quadro da construção europeia da União Económica e Monetária, os processos de liberalização, privatização e (re)regulamentação do setor financeiro, assim como a criação da moeda única europeia, permitiram o acesso da banca portuguesa a quantias avultadas de financiamento externo e, por esta via, a concessão de crédito aos agentes domésticos para a construção e aquisição de novos fogos residenciais (Santos, Teles e Serra, 2014; Rodrigues, Santos e Teles, 2016b). Embora a opção política por um modelo privado de provisão tenha sido sempre dominante (Serra, 2002; Guerra, 2011), o acesso mais facilitado a financiamento externo permitiu sustentar a construção e aquisição de casa própria com recurso ao crédito, que se tornara barato e abundante, sendo este promovido pelo Estado através de importantes bonificações a este tipo de empréstimos e aliciantes incentivos fiscais em sede de IRS. A explosão da oferta de crédito para a compra de casa própria, a que um número crescente de famílias portuguesas conseguiu aceder, alimentou uma significativa dinâmica de investimento na construção, de que resultaram apreciáveis transformações, quantitativas e qualitativas, no parque habitacional, com o crescimento dos alojamentos de residência principal e secundária (Santos, Teles e Serra, 2014).

A estas transformações associaram-se também importantes transformações sociais, sendo, no entanto, os grupos sociais mais privilegiados - os mais ricos, com mais qualificações académicas, mais jovens e com situações profissionais mais estáveis - os que têm uma mais intensa e proveitosa relação com o crédito hipotecário, do qual fazem uma avaliação muito positiva (Ribeiro e Santos, 2018). É, por isso, expectável que esta avaliação positiva se associe a uma melhoria nas condições de habitabilidade, do ponto de vista do conforto do alojamento e/ou das acessibilidades, incluindo outras dimensões de carácter mais subjetivo relacionadas, por exemplo, com a alteração do regime de propriedade do alojamento familiar, o que sugere uma maior discrepância entre proprietários e inquilinos em termos de condições de habitabilidade.

A evolução recente do nexo finança-habitação também aponta para um aumento das desigualdades territoriais, nas áreas metropolitanas e entre elas, que não se manifestam tanto ao nível da participação das famílias no mercado hipotecário em termos agregados, mas sobretudo ao nível da sua composição socioterritorial: revela-se socialmente mais dispersa na AML e mais 
concentrada nos grupos de maior rendimento na AMP (Ribeiro e Santos, 2018). Contudo, estas diferenças encontram-se ainda insuficientemente identificadas. As limitações da base empírica utilizada por Ribeiro e Santos não permitiram analisar a relação entre o crédito à habitação e as suas manifestações e impactos socioterritoriais. Supõe-se, no entanto, que o crescimento do crédito hipotecário tenha tido impactos relevantes na segregação residencial e diferenciação socioterritorial dos espaços metropolitanos. Tendo em conta que as áreas metropolitanas são entidades de natureza política, agregando eventualmente de uma forma arbitrária municípios que não se encontram suficientemente articulados entre si, considera-se que cada área metropolitana é uma unidade de análise relevante para o estudo da financeirização da habitação. Esta presunção justifica-se pela relação privilegiada entre finança e espaço urbano, que oferece as melhores oportunidades para o investimento imobiliário, designadamente em períodos de estagnação ou crise económica, em que o capital não encontra investimentos alternativos suficientemente aliciantes (Harvey, 2010; Aalbers, 2016). No caso nacional, estas oportunidades estão concentradas de forma mais significativa nas duas principiais áreas metropolitanas, como Ribeiro e Santos identificaram no referido estudo exploratório. É esta relação entre finança e espaço urbano que o presente artigo procura explorar no estudo que passamos a descrever de seguida.

\section{CARACTERÍSTICAS SOCIOTERRITORIAIS DA HABITAÇÃO}

\section{NA AML E NA AMP}

Para caracterizar a heterogeneidade socioterritorial das Áreas Metropolitanas de Lisboa e do Porto utilizámos a informação estatística mais recente ao nível da freguesia fornecida pelo Instituto Nacional de Estatística. ${ }^{11}$ Foram selecionados 31 indicadores dos Censos de 2011 (cf. Quadros I e II do anexo) para descrever

11 A escolha da escala geográfica ao nível da freguesia deve-se ao facto de ser esta a escala de menor dimensão para os dados disponíveis (designadamente, os encargos com habitação própria), permitindo dar conta da heterogeneidade socioterritorial, que emergiria esbatida se considerássemos escalas de maior dimensão, como o município ou a região. É este o entendimento da comunidade científica, que aconselha o recurso a escalas de maior detalhe para a caracterização socioeconómica do território (veja-se Ferrão, 2003). Tal opção permite distinguir classes de unidades territoriais do ponto de vista socioeconómico, dentro e entre os municípios e áreas metropolitanas, que não emergiriam se se adotasse outra escala com maior nível de agregação. Assim, de acordo com a última divisão regional portuguesa (Lei n. ${ }^{\circ}$ 75/2013, de 12 de setembro), a AML e a AMP são constituídas por 18 e 17 municípios, respetivamente. Como a informação estatística mais recente ao nível da freguesia é anterior à revisão da divisão regional, foram consideradas em cada município as freguesias definidas pela divisão regional portuguesa de 2002 (Decreto-Lei 244/2002, de 5 de novembro), correspondendo a 211 freguesias para a AML e a 266 para a AMP. 
diferentes dimensões de caracterização socioeconómica das áreas metropolitanas, incluindo aspetos relacionados com a financeirização da habitação, ausentes nas análises semelhantes referidas anteriormente. ${ }^{12}$ Subsequentemente, foram aplicadas análises em componentes principais com rotação varimax aos indicadores selecionados, o que permitiu obter um menor número de dimensões capazes de sintetizar a informação inicial para as duas áreas metropolitanas. Finalmente, recorreu-se à análise de clusters sobre os scores fatoriais ${ }^{13}$ das componentes extraídas pela análise em componentes principais para identificar grupos homogéneos de freguesias em cada área metropolitana. ${ }^{14}$

\section{A Área metropolitanA DE LISBOA}

A análise em componentes principais $\left(\mathrm{KMO}=0.8 \mathrm{O}^{15}\right)$ realizada para as 211 freguesias que constituem a AML extraiu seis componentes com valor próprio superior a um e que explicam $75.8 \%$ da variância total (cf. Quadro I do Anexo), permitindo identificar seis dimensões socioeconómicas. Atendendo às saturações entre os indicadores de base e as componentes extraídas, atribuiu-se a designação seguinte às dimensões socioeconómicas: envelhecimento, qualificação, vulnerabilidade social, classe média, atividade e sazonalidade.

A primeira dimensão remete para o envelhecimento da população e do parque habitacional, associando edifícios antigos, arrendados, vagos, com grandes necessidades de reparação ou muito degradados a uma população envelhecida

12 Foram selecionados indicadores relativos aos indivíduos (idade, ocupação profissional e naturalidade, variáveis 1 a 12), alojamentos familiares (tipo de ocupação, encargos com crédito e custos, variáveis 13 a 19), padrões de mobilidade (modo e duração dos movimentos pendulares e mobilidade residencial, variáveis 20 a 26), e edifícios (tipo de uso e construção recente, variáveis 27 a 31 nos quadros I e II). Naturalmente, a seleção dos indicadores foi condicionada pelos indicadores censitários disponíveis. No entanto, considera-se que os mesmos permitem caracterizar, tanto do ponto de vista socioeconómico como habitacional, a AML e a AMP. Acresce que esta análise beneficia do exercício comparativo com estudos realizados com propósitos semelhantes (por exemplo Alves, 2016; INE, 2014; Santos, 2016), ainda que se distinga dos demais pela inclusão de variáveis referentes à propriedade e tipo de encargos com a habitação, como referimos.

13 Os scores fatoriais, obtidos através do método de regressão, são variáveis estandardizadas com média igual a zero e desvio-padrão igual a um.

14 A identificação dos centróides iniciais e a decisão sobre o número de clusters foi tomada com base na análise de clusters hierárquica com o método de Ward, usando a distância euclidiana quadrada como medida de dissemelhança. A inclusão final das freguesias em cada cluster foi obtida pela aplicação posterior do procedimento não-hierárquico K-médias, conforme a abordagem sugerida por Hair et al. (2005). Para a comparação entre clusters recorreu-se ao teste de Kruskal-Wallis e a estatística descritiva. Todas as análises estatísticas foram realizadas utilizando o software IBM SPSS Statistics v. 24.

15 O valor de 0.80 no teste de Kaiser-Meyer-Olkin indica que os dados são adequados para a realização da análise em componentes principais. 
e de imigração europeia, mas também à diversidade funcional do edificado e à capacidade de atração de novos residentes. A segunda refere-se à qualificação da população e associa uma população com educação de nível superior, com atividade profissional executiva ou intelectual e científica no setor terciário, ${ }^{16}$ a rendas elevadas dos alojamentos familiares clássicos. A terceira dimensão refere-se a vulnerabilidade social e associa alojamentos sobrelotados, altos níveis de desemprego e uso de transportes públicos nos movimentos pendulares, a população de naturalidade africana. Associa ainda, de forma negativa, edifícios construídos nos últimos 10 anos. A proporção de alojamentos ocupados pelo proprietário com hipoteca está associada à quarta e quinta dimensão. A quarta dimensão classe média - associa população com ocupações de nível intermédio ${ }^{17}$ a movimentos pendulares de maior duração. Esta dimensão associa ainda, de forma negativa, custos com hipotecas e população empregada no setor primário. Por seu lado, a quinta dimensão - atividade - associa as hipotecas à taxa de atividade e capacidade de atração de população de outros municípios. Finalmente, a sexta dimensão remete para sazonalidade, associando alojamentos de uso sazonal e estabelecimentos hoteleiros a população de naturalidade brasileira.

O dendrograma produzido pela análise hierárquica aplicada aos scores fatoriais sugeriu a retenção de seis classes de freguesias (clusters) que explicam $51 \%$ da variância total ( $\mathrm{R}$ quadrado $=0.51$ ). A figura 1 apresenta a localização das freguesias classificadas em cada cluster, obtida pela aplicação do método não hierárquico $\mathrm{K}$-médias $(\mathrm{K}=6) .{ }^{18}$

O quadro 1 apresenta os centróides das seis dimensões socioeconómicas extraídas pela análise em componentes principais para cada classe socioeconómica do território, que indicam os desvios médios de cada cluster em relação à média (zero) do total de freguesias. $\mathrm{O}$ quadro 2 apresenta as medianas de uma seleção de indicadores, ${ }^{19}$ que permite identificar com um pouco de mais detalhe as diferenças entre estas classes.

16 Corresponde a população empregada inscrita nos grupos 1 e 2 da Classificação Nacional de Profissões: representantes do poder legislativo e de órgãos executivos, dirigentes, diretores e gestores executivos e especialistas das atividades intelectuais e científicas.

17 Corresponde à população empregada inscrita nos grupos 3 a 5 da Classificação Nacional de Profissões: Técnicos e profissões de nível intermédio, pessoal administrativo e trabalhadores dos serviços pessoais, de proteção e segurança e vendedores.

18 Os resultados revelam que a distribuição das freguesias pelas classes (clusters) não é independente do município, $\chi^{2}(85)=302.67, p<.001$, e que as seis dimensões de categorização socioterritorial permitem distinguir os seis espaços territoriais identificados na análise de clusters, $H(5), p<.05$.

19 Como alguns indicadores apresentam desvios à normalidade da distribuição, optou-se pela apresentação das medianas. 
FIGURA 1

Tipologia socioterritorial da AML, 2011
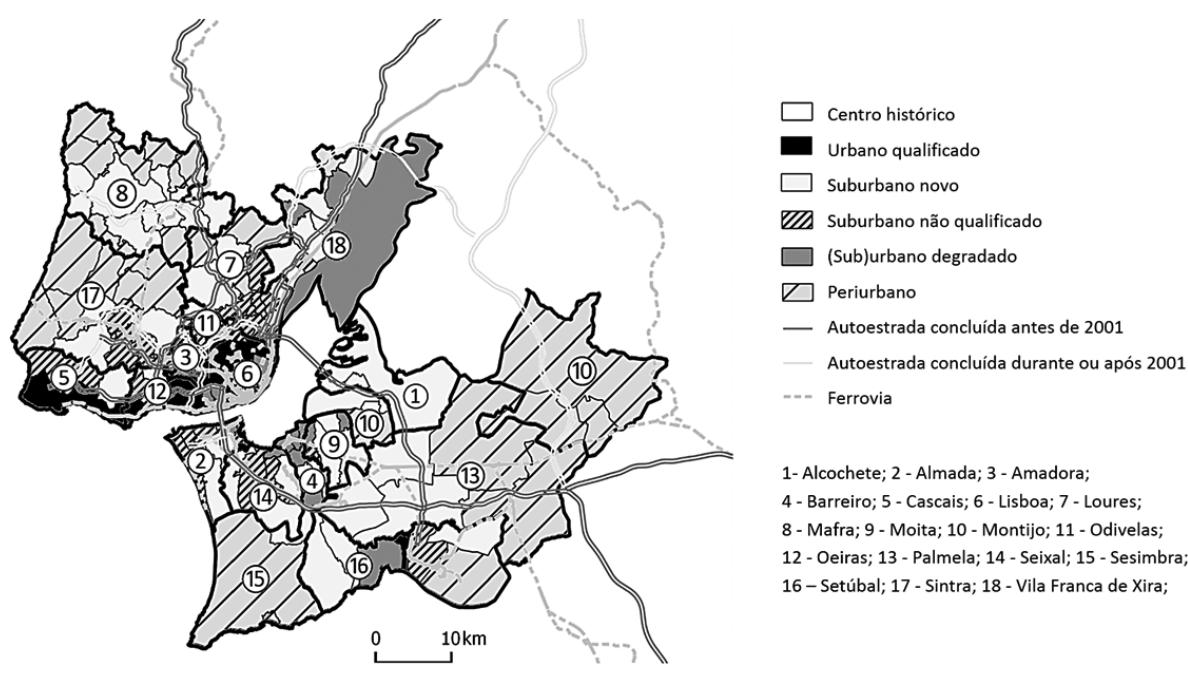

1- Alcochete; 2 - Almada; 3 - Amadora;

4 - Barreiro; 5 - Cascais; 6 - Lisboa; 7 - Loures;

8 - Mafra; 9 - Moita; 10 - Montijo; 11 - Odivelas;

12 - Oeiras; 13 - Palmela; 14 - Seixal; 15 - Sesimbra;

16 - Setúbal; 17 - Sintra; 18 - Vila Franca de Xira;

QUADRO 1

Centróides das classes socioterritoriais da AML, 2011

\begin{tabular}{|c|c|c|c|c|c|c|c|}
\hline & \multicolumn{6}{|c|}{ CLASSES } \\
\hline & & $\begin{array}{c}\text { Centro } \\
\text { histórico } \\
(n=17)\end{array}$ & $\begin{array}{c}\text { Urbano } \\
\text { qualificado } \\
(n=33)\end{array}$ & $\begin{array}{c}\text { Suburbano } \\
\text { novo } \\
(n=53)\end{array}$ & $\begin{array}{c}\text { Suburbano } \\
\text { não } \\
\text { qualificado } \\
(n=46)\end{array}$ & $\begin{array}{c}\text { (Sub)urbano } \\
\text { degradado } \\
(n=33)\end{array}$ & $\begin{array}{c}\text { Periurbano } \\
\quad(n=29)\end{array}$ \\
\hline \multirow{6}{*}{$\begin{array}{l}\text { 㟧 } \\
\text { 崫 } \\
\frac{\sum}{0}\end{array}$} & Envelhecimento & 2.24 & -0.24 & -0.50 & -0.42 & 0.73 & -0.29 \\
\hline & Qualificação & 0.67 & 1.62 & -0.17 & -0.24 & -0.38 & -1.10 \\
\hline & Vulnerabilidade social & 0.19 & -0.02 & -0.83 & 1.37 & -0.24 & -0.48 \\
\hline & Classe média & -0.29 & -0.51 & 0.42 & 0.30 & 0.97 & -1.61 \\
\hline & Atividade & 0.95 & -0.60 & 0.69 & 0.32 & -1.09 & -0.41 \\
\hline & Sazonalidade & 0.79 & -0.15 & -0.09 & -0.02 & -0.25 & 0.18 \\
\hline
\end{tabular}

O Centro histórico, composto por 17 freguesias do município de Lisboa, caracteriza-se pela dimensão "envelhecimento" dos alojamentos e da população (Quadro 1). Distingue-se ainda por ter uma proporção significativamente mais elevada de alojamentos arrendados ou subarrendados (61.4\%), de edifícios a necessitar de grandes reparações ou muito degradados (12.1\%) e de alojamentos vagos (25.9\%) (Quadro 2). O espaço contíguo ao Centro histórico, designado de Urbano qualificado, agrupa 33 freguesias, principalmente do 
município de Lisboa (60.6\%) e Oeiras (18.2\%), distinguindo-se pela qualificação da população residente, apresentando a maior proporção de categorias profissionais de topo (49.6\%) e os proprietários com os encargos mensais mais elevados para aquisição de casa própria $(498.5 €)$. O espaço Periurbano, que reúne 29 freguesias, principalmente dos municípios de Mafra (27.6\%), Sintra (24.1\%) e Montijo (17.2\%), caracteriza-se por uma relação inversa com as dimensões "qualificação" e "classe média", revelando a proporção mais baixa de alojamentos do próprio com encargos (32.3\%). As restantes três classes apresentam muitas semelhanças entre si, sendo caracterizadas pela dimensão "classe média", que se refere a freguesias cuja população residente é maioritariamente constituída por profissionais intermédios, proprietária de alojamentos familiares com encargos médios mensais de compra relativamente baixos. No entanto, há diferenças assinaláveis entre elas (cf. Quadros 1 e 2).

O espaço Suburbano novo agrupa 53 freguesias de diversos municípios em torno de Lisboa (e.g. Mafra: 17.0\%; Vila Franca de Xira: 11.3\%; Loures: 9.4\%) e distingue-se dos demais pela maior proporção de alojamentos pertencentes aos residentes $(76.3 \%)$, e pela maior proporção de proprietários com encargos relativos à sua aquisição (59.2\%). Este espaço localiza-se maioritariamente ao longo dos eixos de expansão suburbana definidos pelas vias rodoviárias e ferroviárias das linhas de Sintra, Azambuja e Sado, e corresponde a uma zona de construção recente (17.4\%), e em que a superfície média útil $\left(108.2 \mathrm{~m}^{2}\right)$ é a mais elevada entre as áreas consideradas. Estes dois aspetos podem justificar o crescimento populacional mais intenso da última década (9.5\%) e os valores mais elevados de encargos médios mensais com aquisição de casa própria deste espaço (453.8€), face aos outros dois espaços (381.1€ e $384.5 €$ ) (cf. Quadro 2).

O espaço Suburbano não qualificado congrega 46 freguesias, principalmente dos municípios da Amadora (19.6\%), Loures (19.6\%) e Sintra (19.6\%). Este espaço partilha algumas características do Suburbano novo, mas distingue-se dele por uma menor presença de categorias profissionais de topo (16.9\% vs. $23.8 \%)$, maior taxa de desemprego ( $15.1 \%$ vs. $11.5 \%)$ e por uma maior concentração de população de origem africana (12.6\% vs. 4.0\%). A elevada proporção de alojamentos com encargos e a maior incidência de desemprego indiciam uma maior concentração do risco associado ao crédito hipotecário nestas freguesias. Por seu lado, o espaço Urbano e Suburbano degradado, ${ }^{20}$ que reúne 33 freguesias, principalmente do município de Lisboa (42.4\%) e Barreiro (18.2\%), caracteriza-se por uma menor proporção de residentes proprietários

20 Adota-se, para simplificar, a designação (Sub)urbano degradado para denominar ambos os contextos, urbanos e suburbanos. 
QUADRO 2

Alguns indicadores das classes socioterritoriais da AML, 2011 (medianas)

Alojamentos arrendados ou subarrendados (\%)

Alojamentos do próprio (\%)

Alojamentos do próprio com encargos (\%)

Encargos médios mensais com aquisição de casa própria $(€)$

Edifícios construídos nos últimos dez anos (\%)

Edifícios com necessidade de grandes reparações ou muito degradados (\%)

Alojamentos vagos (\%)

Pop. de naturalidade brasileira (\%)

Pop. de naturalidade europeia (\%)

Pop. de naturalidade africana (\%)

Categorias profissionais intermédias (\%)

Categorias profissionais do topo (\%)

Variação da população residente (2001-2011) (\%)

Superfície média útil dos alojamentos familiares $\left(\mathrm{m}^{2}\right)$

(58.7\%) e de proprietários com encargos (49.3\%), apresentando pouca construção recente $(3.5 \%)$, mais alojamentos degradados (7\%) e vagos (16.5\%), (Quadro 2).

Estes dados indicam que o crédito hipotecário na AML está relacionado com o crescimento da área urbana ao longo das principais vias rodoviárias e ferroviárias, onde se concentra a construção de novos alojamentos com uma superfície média útil maior e um custo menor, destinando-se sobretudo aos profissionais intermédios. Os dados reforçam ainda as ideias de heterogeneidade e fragmentação da AML e dos seus municípios. A cidade de Lisboa, por exemplo, é constituída por três espaços distintos. O Centro histórico (que inclui as atuais freguesias da Misericórdia e Arroios, boa parte da atual freguesia de Santa Maria Maior, e as antigas freguesias de Santos-o-Velho (parte da Estrela) e Coração de Jesus (parte da atual freguesia de Santo António), as freguesias pertencentes ao Urbano qualificado e as freguesias pertencentes (Sub)urbano degradado, que se caracterizam por degradação urbana e abandono do edificado. Embora estas freguesias estejam a perder população, não deixam de 


\begin{tabular}{cccccc}
$\begin{array}{c}\text { Centro } \\
\text { histórico }\end{array}$ & $\begin{array}{c}\text { Urbano } \\
\text { qualificado }\end{array}$ & $\begin{array}{c}\text { Suburbano } \\
\text { novo }\end{array}$ & $\begin{array}{c}\text { Suburbano } \\
\text { não qualificado }\end{array}$ & $\begin{array}{c}\text { (Sub)urbano } \\
\text { degradado }\end{array}$ & Periurbano \\
\hline 61.4 & 29.4 & 17.4 & 27.9 & 35.3 & 17.2 \\
32.5 & 64.1 & 76.3 & 64.4 & 58.7 & 71.3 \\
51.4 & 46.2 & 59.2 & 55.6 & 49.3 & 32.3 \\
495.3 & 498.5 & 453.8 & 381.1 & 384.5 & 497.5 \\
3.3 & 7.1 & 17.4 & 6.3 & 3.5 & 11.1 \\
12.1 & 3.2 & 2.8 & 3.9 & 7.0 & 3.4 \\
25.9 & 13.2 & 11.8 & 11.4 & 16.5 & 12.8 \\
\hline 5.0 & 2.3 & 1.7 & 2.5 & 2.5 & 1.6 \\
3.3 & 1.6 & 1.2 & 0.8 & 0.9 & 0.9 \\
5.9 & 5.6 & 4.0 & 12.6 & 4.4 & 1.5 \\
41.2 & 38.8 & 46.2 & 48.5 & 48.7 & 36.3 \\
43.0 & 49.6 & 23.8 & 16.9 & 24.9 & 17.1 \\
\hline 8.9 & -1.0 & 9.5 & 1.1 & -5.5 & 9.5 \\
84.6 & 104.5 & 108.2 & 86.6 & 81.2 & 104.2 \\
\hline
\end{tabular}

ter capacidade de atração de população qualificada, que anteriormente residia em outros municípios, e população imigrante de naturalidade europeia e brasileira. O Centro histórico apresenta também uma elevada concentração de alojamentos destinados ao turismo e de ocupação sazonal. Além do mais, atravessa atualmente um processo acelerado de renovação impulsionado pelo aumento do turismo, como o número em crescimento galopante de alojamentos hoteleiros e de estabelecimentos de alojamento local atestam, sobretudo nas freguesias de Santa Maria Maior e Misericórdia (Barata-Salgueiro, 2017). ${ }^{21}$ Nas freguesias que compõem o Urbano qualificado, o crédito hipotecário está associado a um segmento alto do mercado de habitação, que se destina a uma população qualificada que tem capacidade de suportar encargos

21 Nas freguesias de Santa Maria Maior e Misericórdia a percentagem de apartamentos turísticos em 2017 correspondia a 18\% e 15\% do parque habitacional (segundo os Censos 2011), respetivamente. A freguesia de Santo António possuía, em 2016,30\% das unidades hoteleiras do município de Lisboa e a freguesia de Arroios 11\% (INE, 2018). 
elevados com aquisição de casa própria. Contudo, neste espaço a maior parte dos proprietários não tem encargos com hipotecas, podendo isso dever-se ou a uma participação anterior no mercado hipotecário ou a uma maior capacidade económica que permitiu a aquisição de casa própria sem recurso ao crédito.

Por último, o Periurbano apresenta a mais baixa percentagem de alojamentos com encargos de crédito, sendo estes, no entanto, elevados. A também elevada proporção de alojamentos de uso sazonal neste espaço sugere que o processo de financeirização da habitação neste território poderá estar mais intensamente associado à aquisição de segundas habitações.

\section{A Área metropolitana do porto}

A análise em componentes principais realizada para as 266 freguesias que constituem a AMP $(\mathrm{KMO}=0.80)$ extraiu cinco componentes com valor próprio superior a 1.38, que explicam 69.2\% da variância total (ver Quadro II do anexo). A primeira dimensão, Qualificação e dinamismo, associa uma população com formação de nível superior, empregada em profissões intermédias e de topo no setor terciário, à capacidade de atração de população de origem africana e brasileira, valores elevados dos alojamentos arrendados e hipotecas. A segunda dimensão, Envelhecimento, associa edifícios arrendados, antigos, degradados, sobrelotados, vagos ou destinados à hotelaria a uma elevada taxa de desemprego. A terceira dimensão remete para a Ruralidade, associando uma população envelhecida, inativa e com ocupação no setor primário a edifícios de uso sazonal. Já a quarta dimensão, Mobilidade pendular, é caracterizada por movimentos pendulares de longa duração e pelo uso do transporte público nas deslocações para o local de trabalho ou estudo. Por último, a quinta dimensão, Baixa densidade, associa edifícios não exclusivamente residenciais a baixos encargos com hipotecas e deslocações pedonais.

Tal como para a AML, o dendrograma produzido pela análise hierárquica de clusters sugeriu a retenção de seis classes, explicando $53 \%$ da variância total ( $\mathrm{R}$ quadrado $=0.53$ ). A solução final de cluster resultante da aplicação do método $\mathrm{K}$-médias é apresentada na figura $2 .{ }^{22}$

Enquanto na AML a heterogeneidade e fragmentação dos espaços metropolitanos ocorre em torno dos eixos de expansão suburbana que se formam a partir dos territórios limítrofes ao município de Lisboa, tanto a norte do Tejo, como na margem sul, na AMP o processo de suburbanização marca mais vincadamente a oposição centro-periferia, e uma expansão circunferencial em

22 Também na AMP a distribuição das freguesias pelos clusters não é independente do município, $\chi^{2}(80)=447.84, p<.001$, e é possível observar diferenças socioeconómicas entre as classes territoriais identificadas, $H(5), p<.05$. 
FIGURA 2

Tipologia socioterritorial da AMP, 2011

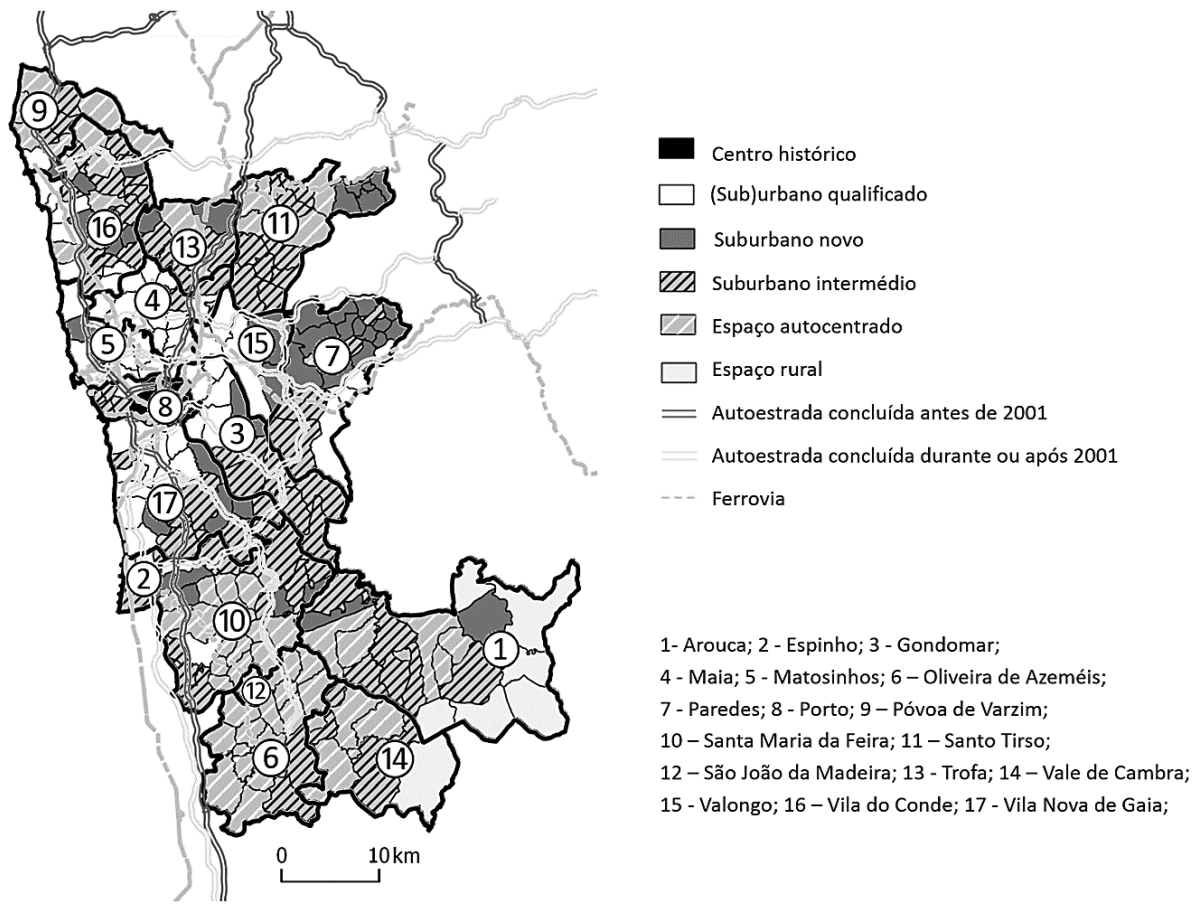

torno do município do Porto. ${ }^{23}$ Nesta medida, os principais contrastes na AMP encontram-se entre o Centro histórico e a periferia mais distante, que designamos de Espaço rural.

O Espaço rural agrupa sete freguesias pertencentes aos municípios de Arouca ( $85.7 \%)$ e Vale de Cambra (14.3\%) e reflete essencialmente a dimensão "ruralidade", com população idosa, inativa, ou pouco qualificada, empregada no setor primário e habitação de uso sazonal. Pelo contrário, o Centro histórico reúne dez freguesias do município do Porto e representa o centro urbano consolidado da AMP, sendo simultaneamente caracterizado pelas dimensões "envelhecimento" e "qualificação e dinamismo", coexistindo edificado antigo, vago, com necessidade de grandes reparações ou degradado e sobrelotado, com uma população residente muito qualificada e cosmopolita e recentemente chegada ao município (cf. Quadro 3). A classe (Sub)urbano qualificado caracteriza uma área urbana e suburbana com elevada proporção de alojamentos do próprio com hipoteca, correspondendo a uma população residente jovem, ativa e qualificada. Reúne 58 freguesias, principalmente dos municípios da

23 Tal como já havia sido identificado em INE (2014). 
QUADRO 3

Centróides das classes socioterritoriais da AMP, 2011

\begin{tabular}{|c|c|c|c|c|c|c|c|}
\hline & \multicolumn{6}{|c|}{ CLASSES } \\
\hline & & $\begin{array}{l}\text { Espaço } \\
\text { Rural } \\
(\mathrm{n}=7)\end{array}$ & $\begin{array}{c}\text { Espaço } \\
\text { autocen- } \\
\text { trado } \\
(\mathrm{n}=68)\end{array}$ & $\begin{array}{c}\text { Suburbano } \\
\text { novo } \\
(n=44)\end{array}$ & $\begin{array}{c}\text { Suburbano } \\
\text { intermédio } \\
\quad(n=79)\end{array}$ & $\begin{array}{c}\text { (Sub)urbano } \\
\text { qualificado } \\
(n=58)\end{array}$ & $\begin{array}{c}\text { Centro } \\
\text { histórico } \\
(n=10)\end{array}$ \\
\hline \multirow{5}{*}{ 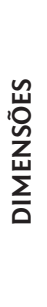 } & $\begin{array}{l}\text { Qualificação } \\
\text { e dinamismo }\end{array}$ & -0.71 & -0.15 & -0.75 & -0.39 & 1.16 & 1.18 \\
\hline & Envelhecimento & -0.96 & -0.38 & 0.16 & 0.03 & -0.25 & 3.78 \\
\hline & Ruralidade & 4.20 & -0.09 & -0.67 & 0.22 & -0.40 & 1.23 \\
\hline & Mobilidade pendular & 0.87 & -0.99 & -0.26 & 0.42 & 0.75 & -0.36 \\
\hline & Baixa densidade & 1.83 & -0.17 & 0.85 & -0.80 & 0.38 & 0.23 \\
\hline
\end{tabular}

QUADRO 4

Alguns indicadores das classes socioterritoriais da AMP, 2011 (medianas)

Alojamentos arrendados ou subarrendados (\%)

Alojamentos do próprio (\%)

Alojamentos do próprio com encargos (\%)

Encargos médios mensais por aquisição de casa própria $(€)$

Edifícios construídos nos últimos dez anos (\%)

Edifícios com necessidade de grandes reparações ou muito degradados (\%)

Alojamentos vagos (\%)

Índice de envelhecimento $\left(\mathrm{N} .^{\circ}\right)$

Pop. residente que trabalha ou estuda noutro município (\%)

Profissionais intermédios (\%)

Profissionais socialmente mais valorizados (\%)

Taxa de desemprego (\%)

Variação da população residente (2001-2011) (\%)

Superfície média útil dos alojamentos familiares clássicos de residência habitual $\left(\mathrm{m}^{2}\right)$

População empregada no setor primário (\%)

População empregada no setor terciário (\%) 
Maia (22.4\%), Vila Nova de Gaia (20.7\%), Matosinhos (12.1\%) e Vila do Conde (12.1\%). Ao contrário da AML, a financeirização da habitação na AMP é predominante nos municípios (sub)urbanos contíguos à cidade do Porto e nos grupos socioeconómicos mais favorecidos. As outras classes socioterritoriais da AMP apresentam características muito semelhantes entre si, como se pode observar pelo quadro 3. A distinção entre elas requer, por isso, uma análise mais fina dos indicadores do quadro 4.

O espaço Suburbano novo reúne 44 freguesias, principalmente dos municípios de Paredes (36.4\%), Santo Tirso (11.4\%) e Vila do Conde (11.4\%), e distingue-se relativamente dos demais por ter uma população mais jovem (índice 79), o que poderá justificar o maior peso de alojamentos do próprio com encargos (43.8\%) e um maior peso (ligeiro) da construção recente (16.5\%). No entanto, a população em idade ativa é a menos qualificada (11.6\%), o que pode, por sua vez, explicar o valor mais baixo dos encargos com hipotecas nesta classe $(346.0 €)$. No espaço Suburbano intermédio estão reunidas 79

\begin{tabular}{cccccc}
$\begin{array}{c}\text { Espaço } \\
\text { rural }\end{array}$ & $\begin{array}{c}\text { Suburbano } \\
\text { novo }\end{array}$ & $\begin{array}{c}\text { Suburbano } \\
\text { intermédio }\end{array}$ & $\begin{array}{c}\text { Espaço } \\
\text { autocentrado }\end{array}$ & $\begin{array}{c}\text { (Sub)urbano } \\
\text { qualificado }\end{array}$ & $\begin{array}{c}\text { Centro } \\
\text { histórico }\end{array}$ \\
\hline 0.0 & 19.2 & 12.2 & 13.5 & 23.0 & 60.2 \\
\hline 92.5 & 70.2 & 76.7 & 77.5 & 70.6 & 34.5 \\
\hline 5.4 & 43.8 & 31.7 & 37.3 & 58.9 & 47.5 \\
\hline 321.0 & 346.0 & 405.0 & 392.7 & 399.9 & 413.3 \\
\hline 14.4 & 16.5 & 13.3 & 14.5 & 10.8 & 4.4 \\
\hline 5.1 & 4.2 & 3.5 & 3.1 & 4.0 & 8.6 \\
\hline 1.0 & 9.5 & 8.9 & 9.4 & 10.8 & 25.2 \\
\hline 335.7 & 79.0 & 108.3 & 110.0 & 89.2 & 251.7 \\
\hline 23.0 & 27.2 & 32.6 & 25.8 & 42.0 & 19.7 \\
\hline 16.3 & 29.3 & 31.6 & 30.2 & 42.6 & 44.9 \\
\hline 12.7 & 11.6 & 16.5 & 15.2 & 24.5 & 30.7 \\
\hline 8.2 & 16.3 & 15.5 & 9.8 & 15.8 & 22.1 \\
\hline-25.2 & 1.0 & -4.0 & -3.3 & 8.7 & -15.4 \\
\hline 102.8 & 110.4 & 120.1 & 123.7 & 109.6 & 83.6 \\
\hline 23.3 & 1.3 & 1.9 & 1.1 & 0.6 & 0.2 \\
\hline 34.2 & 48.6 & 54.1 & 47.1 & 74.2 & 87.2 \\
\hline
\end{tabular}


freguesias, principalmente dos municípios de Vila do Conde (16.5\%), Santo Tirso (13.9\%), Santa Maria da Feira (12.7\%) e Vila Nova de Gaia (10.1\%). É um espaço suburbano essencialmente residencial com encargos com hipotecas relativamente mais elevados (405.0€), o que pode ser explicado pelo nível mais elevado de qualificação profissional (16.5\%) e de emprego no setor terciário (54.1\%) dos seus residentes. O Espaço autocentrado reúne 68 freguesias, principalmente dos municípios de Oliveira de Azeméis (25.0\%), Santa Maria da Feira (23.5\%), Santo Tirso (11.8\%) e Póvoa de Varzim (10.3\%) e distingue-se dos demais pela menor proporção de população que trabalha ou estuda noutro município (25.8\%) (cf. Quadro 4). Em suma, a comparação entre os vários espaços suburbanos sugere que o espaço Suburbano novo apresenta, apenas de forma incipiente, a evolução observada nas áreas suburbanas da $\mathrm{AML}$, nomeadamente a relação entre crédito hipotecário, construção recente, menores encargos de aquisição e classe média.

\section{AS ÁREAS METROPOLITANAS DE LISBOA E PORTO}

No prefácio do estudo do INE (2014), João Ferrão explica as diferenças encontradas entre a AML e a AMP na natureza estruturalmente diversa dos processos de metropolitanização de cada uma. Enquanto na AML estes processos são "mais antigos, mais amplos, socialmente mais diferenciados e se baseiam na transformação sistemática do solo rural em solo urbano" (p. 9), na AMP estes

FIGURA 3

Encargos médios mensais por aquisição de casa própria $(€)$ vs. duração de movimentos pendulares (min), AML, 2011

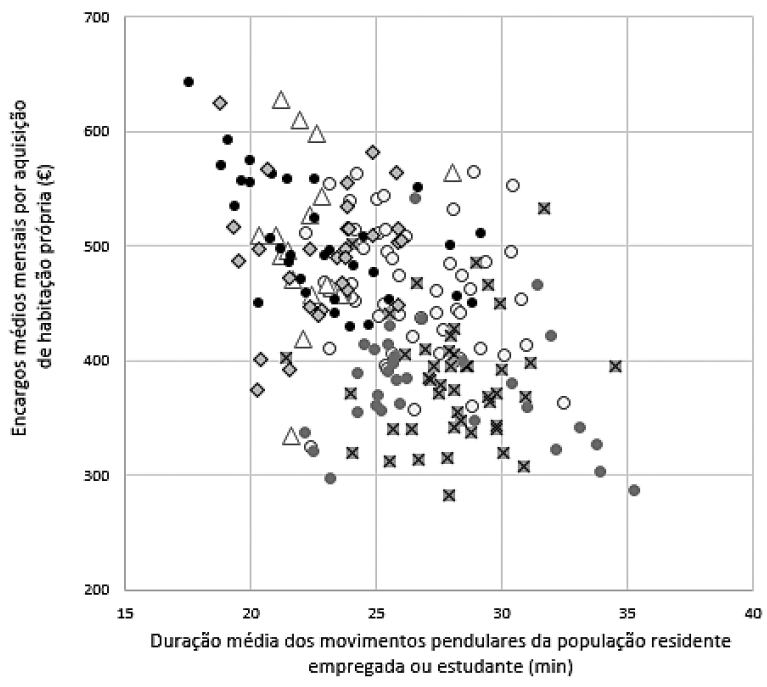

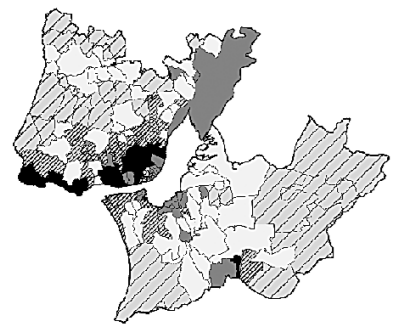

$\triangle \square$ Centro histórico

- Urbano qualificado

- $\square$ Suburbanonovo

× $\mathbb{Z}$ Suburbano não qualificado

- $\square$ (Sub)urbano degradado

$\diamond \square$ Periurbano 
processos ocorreram "de forma mais tardia e contida", incluindo "processos de urbanização in situ, não baseados em movimentos pendulares de grande amplitude entre os locais de residência e de trabalho e sem uma presença relevante de comunidades migrantes" (idem).

Estas diferenças também ressaltam na nossa análise. O estudo aqui realizado sugere ainda que o crédito à habitação teve um papel relevante no processo de metropolitanização da AML, acentuando as suas diferenças relativamente à AMP. Enquanto a expansão do crédito hipotecário na AML está associada a construção nova ao longo dos principais eixos rodoviários e ferroviários e diz predominantemente respeito à classe média, na AMP a expansão do crédito hipotecário é um fenómeno mais circunscrito aos municípios vizinhos da cidade do Porto e está associado não apenas à classe média, mas sobretudo aos estratos socioprofissionais mais elevados.

De certo modo, poder-se-á concluir que a financeirização da habitação deixa uma marca mais visível na produção do espaço urbano e suburbano na AML, estabelecendo uma relação mais direta entre a participação da classe média no mercado hipotecário, nova construção e dispersão da população pela área metropolitana. Esta relação, por sua vez, sugere modos de vida diferenciados, desde logo em mais tempo despendido em movimentos pendulares por parte de indivíduos e famílias que adquiriram casas mais novas e baratas nos subúrbios da metrópole. Esta relação é inexistente na AMP quando

FIGURA 4

Encargos médios mensais por aquisição de casa própria (€) vs. duração de movimentos pendulares (min), AMP, 2011
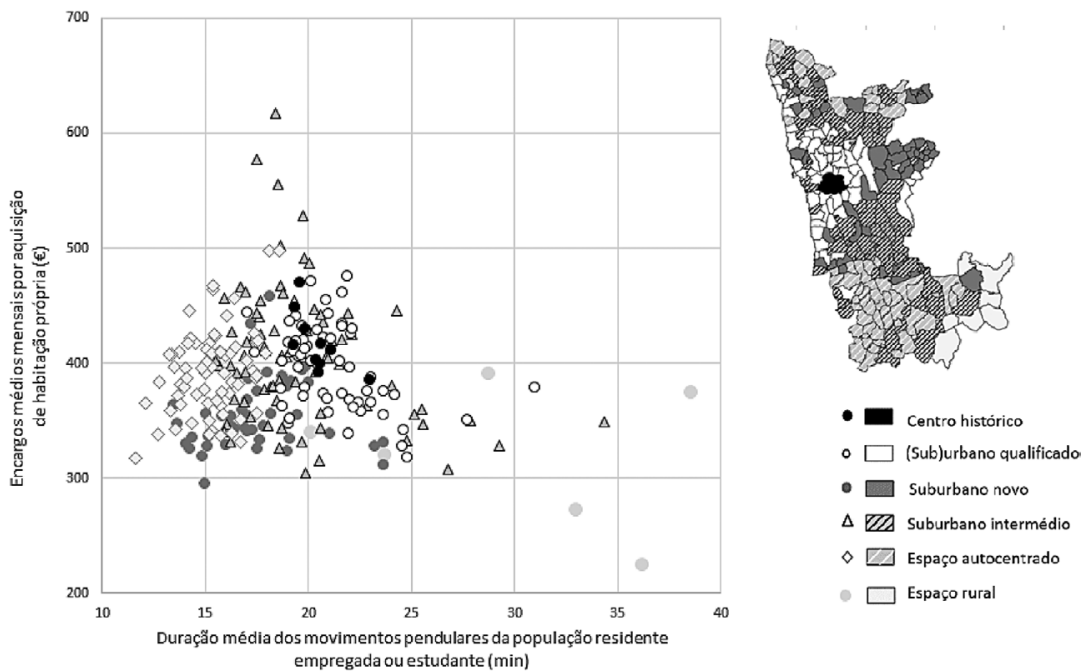
considerada no seu todo. Como as figuras 3 e 4 ilustram, a correlação negativa entre encargos médios mensais por aquisição de casa própria e a duração média dos movimentos pendulares apenas se verifica na AML $\left(r_{s}=-.47\right.$, $p<.001)$, correspondendo os encargos mais baixos aos residentes Suburbanos não qualificados (por exemplo, Frielas: 282.7€; Olival de Basto: $307.4 €$ ) e os mais elevados ao Urbano qualificado (por exemplo, São Sebastião da Pedreira: 643.2€; Lapa: 575.5€). Os espaços Urbanos degradados constituem a exceção à tendência geral, associando encargos relativamente baixos a tempos de deslocação reduzidos (por exemplo, Socorro: $334.3 €$ e 21.6 minutos; Santa Justa: $418.8 €$ e 22.0 minutos). Pelo contrário, na AMP são pouco expressivos os movimentos pendulares de longo alcance, facto que já se verificava em 2001 (Nunes, Mota e Campos, 2012), e a ausência de relação destes com o preço da habitação $\left(r_{\mathrm{s}}=.01, n s\right)$.

\section{A FINANCEIRIZAÇÃO E ÁREA METROPOLITANAS: NOTAS FINAIS}

Como estudos anteriores haviam demonstrado (INE, 2014; Alves, 2016; Santos, 2016), as análises que efetuámos a partir dos Censos de 2011 também dão conta da heterogeneidade e fragmentação das duas áreas metropolitanas em termos da composição sociodemográfica da população residente e das características dos alojamentos familiares, sendo a heterogeneidade e a fragmentação substancialmente mais acentuadas na AML do que na AMP.

Importa salientar uma diferença da análise aqui apresentada relativamente ao estudo do INE, que também inclui as duas áreas metropolitanas. O estudo do INE privilegia uma abordagem integrada dos dois espaços, considerando as mesmas dimensões de caracterização socioeconómica para identificar aspetos diferenciadores e comuns às duas áreas metropolitanas. No presente trabalho, optámos por realizar análises em componentes principais separadas para cada área metropolitana, tendo em vista identificar processos de organização territorial intrínsecos a cada uma delas. Incluíram-se ainda indicadores relativos ao crédito para aquisição de casa própria, variáveis que segundo sabemos não haviam sido ainda estudadas, o que permitiu identificar intensidades diferentes de habitação financeirizada na AML e na AMP, e as dinâmicas específicas que melhor se associam ao crédito hipotecário em cada território.

Constatou-se que o recurso ao crédito para compra de habitação própria se encontra mais generalizado na $\mathrm{AML}$, estendendo-se também às classes médias e concentrando-se mais nas categorias profissionais mais qualificadas na AMP. Estes aspetos suportam os resultados exploratórios de um estudo anterior que identificava uma relação mais forte e diversificada das famílias com a finança na AML (Ribeiro e Santos, 2018). A análise territorial do crédito hipotecário, 
por sua vez, sugere que este está associado ao crescimento em expansão da AML em torno dos principais eixos rodoviários e ferroviários. Na AMP, o crédito hipotecário encontra-se relativamente concentrado nos municípios contíguos à cidade do Porto, tendo pouca expressão nos restantes espaços suburbanos e rurais. Quer isto dizer que na AML a relação entre hipotecas, grupos socioprofissionais e territórios descreve um movimento de expansão na área metropolitana, enquanto na AMP esta relação desenrola-se em torno do núcleo urbano mais consolidado.

Estes resultados levam-nos a concluir que o processo de metropolitanização da AML está intrinsecamente associado ao processo de financeirização da habitação, sendo um elemento relevante do crescimento em expansão desta área metropolitana, não se verificando uma relação tão evidente entre financeirização e metropolitanização na AMP. A estes processos diferenciais não será alheia a controvérsia levantada por diversos autores quanto aos limites territoriais da AMP, baseados mais em lógicas políticas do que em critérios de integração territorial (por exemplo, Barata-Salgueiro, 1992; Gato, 2013). Como se poderão relacionar com o precoce desenvolvimento demográfico e a expansão urbana dos municípios periféricos à cidade do Porto, que remontam ao início do século $\mathrm{xx}$, e a sua relativa independência do centro devido, em grande parte, às características do tecido produtivo industrial da AMP (Vázquez, 1992), num processo de urbanização fragmentado, extensivo e difuso, e que contrasta com um processo mais concentrado e mais recente da AML impulsionado por importantes movimentos migratórios (Barata-Salgueiro, 2001; Marques, 2002; Gato, 2013).

Não será também irrelevante o facto de que entre 2001 e 2011 a AMP registou um acréscimo populacional relativo de apenas $1.7 \%$, comparativamente aos 6.0\% da AML (INE, 2014), apresentando a AML em 2011 maior concentração populacional (congregando $27 \%$ da população em $4 \%$ do território), de emprego ( $29 \%$ do total), de emprego no setor financeiro e imobiliário $(54 \%$ e $39 \%$ respetivamente), e do produto interno bruto (38\%). ${ }^{24}$ Assim, a par de uma relação mais forte entre finança e habitação, que se reflete num maior volume de construção, expansão urbana e crédito à habitação, verifica-se também maior peso e concentração das atividades financeiras neste território, expondo uma maior e profunda inter-relação entre as diversas dimensões do processo de financeirização.

24 Cf. http://appsso.eurostat.ec.europa.eu/nui/show.do?dataset=met_pjanaggr3\&lang=en, http://appsso.eurostat.ec.europa.eu/nui/show.do?dataset=met_d3area\&lang=en, http://appsso. eurostat.ec.europa.eu/nui/show.do?dataset=met_1or_3emp\&lang=en, e http://appsso.eurostat. ec.europa.eu/nui/show.do?dataset=met_1or_3gdp\&lang=en (consultado a 21-03-2018). 
Este estudo vai ao encontro da literatura da financeirização que vem sublinhando a importância de se ter em conta a variedade dos contextos institucionais, político-culturais e territoriais para explicar não só a variedade, em termos de forma e conteúdo, das grandes tendências sistémicas que lhe estão subjacentes, mas também para melhor compreender e explicar os seus impactos desiguais (French, Leyshon e Wainwright, 2011; Fernandez e Aalbers, 2016; Aalbers, 2017). Estas diferenças já começaram a ser identificadas no contexto português, destacando-se a natureza semiperiférica da economia e o papel da integração europeia no seu processo de financeirização, que contrasta com a experiência dos países do Centro europeu (Rodrigues, Santos e Teles, 2016a, 2016b). Também já se encetou a análise da financeirização de sistemas de provisão particulares, como a habitação, a água e as pensões, que têm de levar em linha de conta a natureza específica do bem produzido (Rodrigues, Santos e Teles, 2017; Santos, Rodrigues e Teles, 2017).

Mas o presente artigo explora uma nova dimensão. Chama a atenção para a importância de considerar outras escalas de análise, para lá da unidade nacional, isto é, dos sistemas de provisão de habitação nacionais e o papel da finança em cada um deles. A comparação entre as duas áreas metropolitanas mostra bem que o processo de financeirização não é um processo uniformizador, apontando para um estádio último para o qual todos os outros espaços convergem. Pelo contrário, o processo de financeirização interage com outros processos em curso, podendo até intensificar lógicas preexistentes, dessa forma fazendo perdurar e até mesmo acentuar as divergências. De igual modo, a análise da habitação oferece um excelente exemplo da relevância da inclusão de outras escalas. Sendo certo que a habitação teve um papel central na financeirização da economia e da sociedade portuguesa, associando-se ao extraordinário crescimento do endividamento privado, de empresas e famílias, o presente estudo mostra que a financeirização da habitação teve também um papel fundamental na produção de territórios urbanos, suburbanos e periurbanos. Mostra, também, que este papel foi desigual, tendo sido particularmente intenso e por isso assumido maior impacto socioterritorial na AML.

Antes de concluir, importa referir que a análise efetuada se reporta ao ano de 2011 e que, entretanto, a AML e a AMP têm sido objeto de profundas transformações, nomeadamente de índole turística, sendo de esperar que o retrato que aqui se traçou dos centros históricos se encontre bastante desatualizado. De facto, não é arriscado supor que os novos processos de produção de espaço urbano assentes no crescimento de residentes estrangeiros e na explosão do turismo têm uma natureza substancialmente diferente dos processos inerentes ao crédito hipotecário. Em todo o caso, a evolução e os impactos destes novos movimentos não serão alheios à composição socio-residencial do território 
que aqui se traçou e que seguramente continuará a marcar a composição das desigualdades socioterritoriais.

Finalmente, uma última nota para os grupos mais vulneráveis, que foram certamente os mais afetados pelas dinâmicas tratadas no presente artigo. Os resultados encontrados revelaram que o acesso mais generalizado ao crédito hipotecário está associado a uma maior heterogeneidade e fragmentação socioterritorial, que terão impactos mais negativos nos grupos sociais mais vulneráveis, nomeadamente a contração do mercado de arrendamento que lhe está subjacente e a consequente subida dos preços das rendas. Contudo, o escrutínio destes impactos requer outro tipo de análises, que a metodologia que aqui se adotou, por se basear em análise de variáveis agregadas e seus valores médios, não permitiu captar. 
ANEXO QUADRO I - Solução da análise em componentes principais após rotação, $\mathrm{AML}$

Envelhecimento (22.60 \% da variância explicada)

30. Alojamentos familiares clássicos vagos (\%)

13. Alojamentos familiares clássicos arrendados ou subarrendados (\%)

15. Idade média dos edifícios (ano)

22. Meio de transporte mais utilizado nos movimentos pendulares - nenhum (a pé) (\%)

20. Meio de transporte mais utilizado nos movimentos pendulares - automóvel (\%)

23. População residente que trabalha ou estuda noutro município (\%)

2. Famílias clássicas unipessoais de pessoas com 65 ou mais anos de idade (\%)

1. Índice de envelhecimento $\left(\mathrm{N} .{ }^{\circ}\right)$

16. Edifícios com necessidade de grandes reparações ou muito degradados (\%)

25. População residente que um ano antes residia noutra unidade territorial (\%)

29. Edifícios não exclusivamente residenciais (\%)

10. População residente de naturalidade estrangeira - Europa (\%)

Qualificação (14.10 \% da variância explicada)

9. População residente com ensino superior completo (\%)

5. Profissionais socialmente mais valorizados (\%)

8. População empregada no setor terciário (\%)

18. Valor médio mensal das rendas dos alojamentos familiares clássicos arrendados (€)

Vulnerabilidade social ( 11.15 \% da variância explicada)

11. População residente de naturalidade estrangeira - África (\%)

17. Alojamentos sobrelotados (\%)

4. Taxa de desemprego (\%)

21. Meio de transporte mais utilizado nos movimentos pendulares - transporte público (\%)

31. Edifícios construídos nos últimos dez anos (\%)

Classe média (10.51 \% da variância explicada)

6. Profissionais intermédios (\%)

24. Duração média dos movimentos pendulares da população residente empregada ou estudante (min)

7. População empregada no setor primário (\%)

19. Encargos médios mensais por aquisição de habitação própria (€)

Atividade (10.51 \% da variância explicada)

3. Taxa de atividade (\%)

26. População residente que cinco anos antes residia fora do município (\%)

14. Alojamentos do próprio com encargos (\%)

Sazonalidade (6.94 \% da variância explicada)

27. Alojamentos familiares clássicos de uso sazonal (\%)

12. População residente de naturalidade estrangeira - Brasil (\%)

28. Estabelecimentos hoteleiros e similares $\left(\mathrm{N} .{ }^{\circ}\right)$ 


\section{Componente}

3

4

5

6

$\begin{array}{llllll}0.86 & 0.05 & -0.16 & -0.08 & 0.16 & -0.04 \\ \mathbf{0 . 8 6} & 0.17 & 0.26 & 0.06 & -0.15 & 0.05 \\ \mathbf{0 . 8 4} & 0.22 & 0.02 & -0.05 & -0.26 & 0.08 \\ \mathbf{0 . 7 4} & 0.02 & 0.35 & 0.15 & -0.15 & 0.21 \\ -\mathbf{0 . 7 0} & 0.01 & -0.55 & -0.33 & 0.19 & -0.09 \\ -\mathbf{0 . 6 8} & -0.19 & 0.06 & 0.39 & 0.27 & -0.07 \\ \mathbf{0 . 6 5} & 0.21 & -0.05 & -0.07 & -0.64 & 0.13 \\ \mathbf{0 . 6 5} & 0.12 & -0.07 & 0.03 & -0.61 & 0.18 \\ \mathbf{0 . 6 4} & -0.07 & 0.06 & 0.02 & 0.07 & -0.02 \\ \mathbf{0 . 6 3} & 0.08 & 0.10 & 0.02 & 0.36 & 0.46 \\ \mathbf{0 . 5 9} & 0.48 & 0.17 & -0.01 & 0.19 & 0.18 \\ \mathbf{0 . 5 4} & 0.50 & -0.18 & -0.16 & 0.21 & 0.25\end{array}$

$\begin{array}{llllll}0.14 & 0.94 & -0.15 & -0.10 & 0.00 & 0.06 \\ 0.22 & 0.90 & -0.24 & -0.14 & -0.08 & 0.06 \\ 0.35 & 0.72 & 0.19 & 0.48 & 0.00 & 0.08 \\ -0.19 & 0.61 & -0.04 & -0.22 & 0.34 & 0.44\end{array}$

$-0.21$

0.20

0.12

0.42

$-0.41$

$-0.13$

$-0.22$

$-0.29$

$-0.34$

$-0.07$

0.07

$-0.49$

0.43

0.11

0.19

0.16

0.02

$-0.27$

0.21

0.02

0.29

0.37

0.80

0.75

0.63

0.60

$-0.54$

0.28

0.22

$-0.16$

$-0.45$

0.00

$-0.17$
$-0.10$

0.07

$-0.11$

0.14

0.55

0.83
0.69

$-0.62$

$-0.55$

0.88

0.60

0.58

$-0.14$

0.75

0.09

0.06

0.69

0.04

.05

0.08

.21

.09

.07

.13

.18

0.02

46

.18

0.25

\section{.44}

$-0.07$

$-0.07$

0.01

$-0.09$

0.04

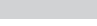

0.04

0.02

0.11

0.10

0.07

0.38

$-0.19$ 


\section{ANEXO QUADRO II - Solução da análise em componentes principais após rotação, AMP}

Qualificação e dinamismo (21.78 \% da variância explicada)

9. População residente com ensino superior completo (\%)

11. População residente de naturalidade estrangeira - África (\%)

5. Profissionais socialmente mais valorizados (\%)

26. População residente que cinco anos antes residia fora do município (\%)

8. População empregada no setor terciário (\%)

12. População residente de naturalidade estrangeira - Brasil (\%)

25. População residente que um ano antes residia noutra unidade territorial (\%)

6. Profissionais intermédios (\%)

14. Alojamentos do próprio com encargos (\%)

18. Valor médio mensal das rendas dos alojamentos familiares clássicos arrendados $(€)^{*}$

Envelhecimento (18.07 \% da variância explicada)

13. Alojamentos familiares clássicos arrendados ou subarrendados (\%)

15. Idade média dos edifícios (Ano)

30. Alojamentos familiares clássicos vagos (\%)

20. Meio de transporte mais utilizado nos movimentos pendulares - automóvel (\%)

16. Edifícios com necessidade de grandes reparações ou muito degradados (\%)

28. Estabelecimentos hoteleiros e similares (N. $\left.{ }^{\circ}\right)$

4. Taxa de desemprego (\%)

17. Alojamentos sobrelotados (\%)

31. Edifícios construídos nos últimos dez anos (\%)

Ruralidade (14.98 \% da variância explicada)

1. Índice de envelhecimento $\left(\mathrm{N} .{ }^{\circ}\right)$

2. Famílias clássicas unipessoais de pessoas com 65 ou mais anos (\%)

3. Taxa de atividade (\%)

27. Alojamentos familiares clássicos de uso sazonal (\%)

7. População empregada no setor primário (\%)

Mobilidade pendular (7.25 \% da variância explicada)

24. Duração média dos movimentos pendulares da população residente empregada ou estudante (min)

21. Meio de transporte mais utilizado nos movimentos pendulares - transporte público (\%)

23. População residente que trabalha ou estuda noutro município (\%)

Baixa densidade (7.14 \% da variância explicada)

19. Encargos médios mensais por aquisição de habitação própria $(€)^{* *}$

10. População residente de naturalidade estrangeira - Europa (\%)

22. Meio de transporte mais utilizado nos movimentos pendulares - nenhum (a pé) (\%)

29. Edifícios não exclusivamente residenciais (\%)

* As freguesias de Albergaria da Serra, Cabreiros, Covelo de Paivó, Janarde e Junqueira tinham valores omissos dado não existire

** A freguesia Albergaria da Serra apresentava valor omisso dada a não existência de alojamentos ocupados pelo proprietário con 


\section{Componente}

$\begin{array}{llllr}\mathbf{0 . 8 8} & 0.10 & 0.01 & 0.05 & -0.22 \\ \mathbf{0 . 8 7} & 0.15 & -0.10 & 0.05 & -0.05 \\ \mathbf{0 . 8 5} & 0.14 & 0.07 & 0.02 & -0.27 \\ \mathbf{0 . 8 2} & 0.05 & -0.12 & 0.11 & -0.02 \\ \mathbf{0 . 7 6} & 0.39 & -0.14 & 0.35 & -0.04 \\ \mathbf{0 . 7 5} & 0.18 & 0.27 & -0.02 & 0.18 \\ \mathbf{0 . 6 6} & 0.41 & -0.26 & -0.10 & 0.07 \\ \mathbf{0 . 6 5} & 0.32 & -0.38 & 0.32 & 0.02 \\ \mathbf{0 . 6 2} & 0.10 & -0.62 & 0.09 & 0.20 \\ \mathbf{0 . 5 9} & -0.27 & -0.05 & -0.23 & -0.16\end{array}$

$\begin{array}{lllll}0.39 & 0.82 & -0.17 & 0.02 & 0.14 \\ 0.18 & 0.76 & 0.32 & 0.05 & 0.04 \\ 0.25 & 0.76 & -0.05 & -0.10 & 0.01 \\ 0.10 & -0.60 & -0.31 & -0.29 & -0.49 \\ -0.06 & 0.59 & 0.10 & 0.00 & 0.03 \\ 0.42 & 0.59 & 0.25 & -0.14 & 0.12 \\ 0.09 & 0.59 & -0.37 & 0.28 & 0.11 \\ -0.24 & 0.52 & -0.06 & 0.25 & 0.47 \\ -0.28 & -0.51 & -0.03 & -0.14 & -0.09\end{array}$

$\begin{array}{lllll}0.04 & 0.35 & 0.82 & -0.02 & 0.04\end{array}$

$\begin{array}{lllll}0.13 & 0.39 & 0.81 & -0.02 & 0.07\end{array}$

$\begin{array}{llll}0.30 & -0.20 & -0.81 & -0.14\end{array}$

$\begin{array}{lllll}0.00 & -0.32 & 0.76 & 0.00 & 0.06\end{array}$

$\begin{array}{lllll}-0.23 & -0.32 & 0.68 & -0.01 & 0.25\end{array}$

$\begin{array}{lllll}0.08 & 0.03 & 0.38 & 0.81 & 0.23 \\ 0.00 & 0.54 & -0.03 & 0.68 & 0.03 \\ 0.27 & -0.22 & -0.27 & 0.57 & 0.00\end{array}$

$\begin{array}{lllll}0.39 & 0.09 & -0.17 & -0.07 & -0.66 \\ 0.12 & -0.18 & 0.10 & -0.25 & -0.56 \\ 0.25 & 0.54 & 0.16 & -0.30 & 0.54 \\ 0.23 & 0.20 & 0.42 & -0.19 & 0.54\end{array}$

m edifícios alugados. Os valores omissos foram substituídos pela média do respetivo município. n hipoteca. O valor omisso foi substituído pela média do respetivo município. 


\section{REFERÊNCIAS BIBLIOGRÁFICAS}

Aalbers, M. B. (2016), The Financialization of Housing: A Political Economy Approach, Londres, Routledge.

AALBERS, M.B. (2017), “The variegated financialisation of housing”. International Journal of Urban and Regional Research, 41(4), pp. 542-554. https://doi.org/10.1111/1468-2427.12522 ALVES, S. (2016), "Spaces of inequality: it's not differentiation, it is inequality! A socio-spatial analysis of the City of Porto". Portuguese Journal of Social Science, 15(3), pp. 409-431. Dor: 10.1386/pjss.15.3.409_1

Barata salgueiro, T. (1992), A Cidade em Portugal: Uma Geografia Urbana, Colecção Cidade em Questão 8, Porto, Edições Afrontamento, $2^{\mathrm{a}}$ edição.

barata Salgueiro, T. (2001), Lisboa, Periferia e Centralidades, Oeiras, Celta Editora.

barata SAlgueiro, T. (2017), "Alojamentos turísticos em Lisboa". Scripta Nova, XXI (578), pp. 1-43. CARmo, R.M., CAchado, R., Ferreira, D. (2015), "Desigualdades em tempos de crise: vulnerabilidades habitacionais e socioeconómicas na Área Metropolitana de Lisboa”. Revista Portuguesa de Estudos Regionais, 40, pp. 5-22.

CAstela, T. (2019), "Cidadania proprietária e emergência da financeirização da habitação em Portugal após 1968”. In A.C. Santos (coord.), A Nova Questão da Habitação em Portugal: Uma Abordagem de Economia Política, Atual Editora, pp. 259-274.

CAStells, M. (1973), La question urbaine, Paris, Maspero.

COSTA, S. (2016), "Situação financeira das famílias em Portugal: uma análise com base nos dados do ISFF 2013”. Revista de Estudos Económicos, 2(4), pp. 15-59.

CRотту, J. (2009), "Structural causes of the global financial crisis: a critical assessment of the new financial architecture". Cambridge Journal of Economics, 33, pp. 563-580.

ePstein, G. A. (2005), Financialization and the World Economy, Aldershot, Edward Elgar.

EUROPEAN CREDIT RESEARCH INSTITUTE (ECRI) (2016), ECRI Statistical Package 2016, Lending to Households and Non-financial Corporations in Europe (1995-2014).

FERNANDEZ, R., AALBERS, M.B. (2016), "Financialization and housing: between globalization and varieties of capitalism". Competition \& Change, 2o(2), pp. 71-88.

fernandez, R., hofman, A., AAlbers, M.B. (2016), "London and New York as a safe deposit box for the transnational wealth elite". Environment and Planning A, 48 (12), pp. 2443-2461.

FERRÃo, J. (2002), "Portugal, três geografias em recombinação: espacialidades, mapas cognitivos e identidades territoriais". Lusotopie, 2, pp. 151-158.

FERRÃO, J. (2003), "Dinâmicas territoriais e trajetórias de desenvolvimento, Portugal 1991-2001". Revista de Estudos Demográficos, 34, pp. 17-25.

FRENCH, S., LEYSHON, A., WAINWRIGHT, T. (2011), "Financializing space, spacing financialization". Progress in Human Geography, 35(6), pp. 798-819.

gato, M. A. (2013), Dinâmicas Populacionais e Habitacionais na Área Metropolitana do Porto, disponível em https://repositorio.iscte-iul.pt/bitstream/10071/5310/1/DINAMIA_R_2013 -03.pdf

GUerra, I. (1997), “Um olhar sociológico sobre o alojamento". Sociologia - Problemas e Práticas, 24 , pp. 165-181.

Guerra, I. (2011), "As políticas de habitação em Portugal: à procura de novos caminhos". Cidades, Comunidades e Territórios, 22, pp. 41-68.

hair, J. F., ANDERson, R.E., TATHAM, R. L., BLACK, W. (2005), Multivariate Data Analysis, Nova Iorque, Pearson. 
Harvey, D. (2010), The Enigma of Capital and the Crisis of Capitalism, Oxford, Oxford University Press.

HaRvey, D. (1973), Social Justice and the City, Oxford, Blackwell.

INSTITUto DA HABItAÇÃo E REABILITAÇÃo URbANA [IHRU] (2015), 1987-2011: 25 Anos de Esforço do Orçamento do Estado com a Habitação, Lisboa, Instituto da Habitação e Reabilitação Urbana, Disponível em https://www.portaldahabitacao.pt/opencms/export/sites/ihr $\mathrm{u} / \mathrm{pt} / \mathrm{ihru}$ /docs/Esforco-do-Estado-em-Habitacao.pdf

INE (2014), Tipologia Socioeconómica das Áreas Metropolitanas de Lisboa e Porto 2011, Lisboa, Instituto Nacional de Estatística.

JORDÀ, Ò., SCHULARICK, M., TAYLOR, A. M. (2015), "Betting the house”. Journal of International Economics, 96, pp. s2-s18.

JORDÀ, Ò., et al. (2017), “The rate of return on everything, 1870-2015”. NBER Working Paper, No. 24112.

Lefebvre, H. (1968), Le droit à la ville, Paris, Éditions Anthropos.

LESTEGAS, I., LOIS-GONZALEZ, R.-C., SEIXAs, J. (2018), “The global rent gap of Lisbon's historic centre". International Journal of Sustainable Development and Planning, 13(4), pp. 683-694.

MALHEIROS, J., valA, F. (2004), "A problemática da segregação residencial de base étnica - questões conceptuais e limites à operacionalização. O caso da Área Metropolitana de Lisboa". Revista de Estudos Demográficos, 36, pp. 89-109.

marques, T.S. (2002), Dinâmicas Territoriais: Portugal na Transição do Século (xx/XXI), Porto, Edição do Autor. Disponível em https://repositorio-aberto.up.pt/handle/10216/20855 [consultado em 04-04-2018].

Nunes, G., мотA, I., CAMPos, P. (2012), "Policentrismo funcional: uma avaliação dos municípios portugueses”. Revista Portuguesa de Estudos Regionais, 29, pp. 27-38.

Ribeiro, R., sANTOS, A.C. (2017), "Custos com a habitação em Portugal e desigualdade territorial". FINHABIT Working Paper, n. ${ }^{\circ} 2$.

Ribeiro, R., SANTOS, A.C. (2018), "Financeirização das famílias e a desigualdade socioeconómica e territorial em Portugal”. Revista Portuguesa de Estudos Regionais, 47, pp. 73-93.

rodrigues, J., SAntos, A.C., Teles, N. (2016a), "Semi-peripheral financialisation: the case of Portugal”. Review of International Political Economy, 23(3), pp. 480-510.

rodrigues, J., santos, A. C., Teles, N. (2016b), A Financeirização do Capitalismo em Portugal, Lisboa, Actual.

RODRIgues, J., SANTOS, A. C., TELES, N. (2017), "Financialisation of pensions in semi-peripheral Portugal". Global Social Policy: An Interdisciplinary Journal of Public Policy and Social Development. http://journals.sagepub.com/doi/10.1177/1468018117742826

santos, A.C., teles, N., serra, N. (2014), "Finança e habitação em Portugal". Cadernos do Observatório sobre Crises e Alternativas, 2, pp. 1-59.

Santos, A.C., Rodrigues, J., teles, N. (2017), "Semi-peripheral financialisation and social reproduction: the case of Portugal”. New Political Economy. https://doi.org/10.1080/135634 67.2017.1371126.

santos, A.C. (2019), "Habitação em tempos financeiros em Portugal”. In A.C. Santos (org.), A Nova Questão da Habitação em Portugal: Uma Abordagem de Economia Política, Lisboa, Actual, pp. 15-52.

SANTOS, S. (2014), "Mobilidade geográfica e desigualdades sociais: lugares e caminhos de investigação sociológica sobre território”, CIES e-Working Paper, n. ${ }^{0}$ 179/2014. Disponível em http://cies.iscte.pt/np4/?newsId=453\&fileName=CIES_WP179_Santos.pdf 
SANTOS, S. (2016), "Who are you calling sub/urban? Socio-spatial inequality and mobility in the Lisbon Metropolitan Area”. Portuguese Journal of Social Science, 15(3), pp. 387-407.

SEIXAS, J. et al. (2015), "Dinâmicas sociogeográficas e políticas na Área Metropolitana de Lisboa em tempos de crise e de austeridade”. Cadernos Metrópole, 17(34), pp. 371-399. http://dx.d oi.org/10.1590/2236-9996.2015-3404.

SERra, N. (2002), Estado, Território e Estratégias de Habitação, Coimbra, Quarteto.

teixeira, M.C. (1992), "As estratégias de habitação em Portugal, 1880-1940". Análise Social, 115 , XXVII (1), pp. 65-89.

vÁzQuez, I. B. (1992), "Crescimento urbano e suburbanização no grande Porto: uma perspectiva relacional”. Análise Social, 115, XXVII (1), pp. 191-205.

Recebido a 05-05-2018. Aceite para publicação a 27-09-2019.

Ribeiro, R., SANTos, A.C. (2019), "Financeirização da habitação e desigualdades socioterritoriais: um

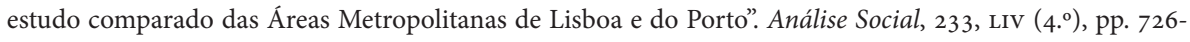
-758 .

Raquel Ribeiro » raquelribeiro@ces.uc.pt » Centro de Estudos Sociais da Universidade de Coimbra » Colégio de S. Jerónimo, Apartado 3087 - 3000-995 Coimbra » https://orcid.org/oooo-0003-4113-0664.

Ana C. Santos » anacsantos@ces.uc.pt »Centro de Estudos Sociais da Universidade de Coimbra »Colégio de S. Jerónimo, Apartado 3087 - 3000-995 Coimbra » https://orcid.org/oooo-0002-3654-2544. 